\title{
Mutation analysis of $P V R L 1$ in patients with non-syndromic cleft of the lip and/or palate in Guangdong
}

\author{
S.Y. Shu*, M.J. Zhang*, H.Q. Cheng*, S.J. Tang, W.L. Chen, S.R. Wu, \\ Y. Lin and Q.S. Chen
}

Cleft Lip and Palate Treatment Center, Second Affiliated Hospital, Shantou University Medical College, Shantou, Guangdong, China

*These authors contributed equally to this study.

Corresponding author: S.J. Tang

E-mail: Tang2302@sina.cn

Genet. Mol. Res. 14 (2): 3400-3408 (2015)

Received August 6, 2014

Accepted December 4, 2014

Published April 15, 2015

DOI http://dx.doi.org/10.4238/2015.April.15.3

\begin{abstract}
Non-syndromic cleft of the lip and/or palate (NSCLP) is a very common birth defect; the poliovirus receptor-like 1 gene (PVRL1) has been identified as a genetic risk factor for NSCLP in patients from Norway, the Philippines, and South America. Given the considerable variation in allele frequencies across these geographical regions, this study explored the relationship between NSCLP and mutations of PVRL1 in patients from Guangdong, China. We recruited 171 NSCLP patients and 100 volunteers, and divided our samples into 2 groups: a sequencing group and a mass spectrometry group. In the sequencing group, we screened for mutations in exons 2 and 5 of PVRL1 by polymerase chain reaction and direct sequencing in 71 NSCLP patients and 100 volunteers. In the mass spectrometry group, we screened for amino acid mutations in $\alpha$-spliced transcript codons 112, 131, and 395, and in the $\beta$-spliced transcript codon 1082 using matrix-assisted laser desorption/ionization time-of-flight mass spectrometry analysis in 100 NSCLP patients and 100 volunteers. No mutations were detected in either
\end{abstract}


PVRL1 exons 2 or 5 in the 71 NSCLP patients and 100 volunteers, nor did we find mutations of $\alpha$-spliced transcript codons 112, 131, 395 and the $\beta$-spliced transcript codon 1082 in any of the 100 NSCLP patients and 100 volunteers. Thus, mutations in exons 2 and 5 of PVRL1, and T334A, A391T, G1183A in the $\alpha$-spliced transcript, and G1082T in the $\beta$-spliced transcript do not participate in the development of NSCLP in patients from Guangdong.

Key words: Mutation; Non-syndromic cleft of the lip and/or palate; PVRL1; Exons

\section{INTRODUCTION}

Cleft of the lip and/or palate [CLP (MIM 119530)] is typically classified in syndromic and non-syndromic forms. Non-syndromic cleft of the lip and/or palate (NSCLP), accounting for $93-95 \%$ of CLP cases, consists of isolated, non-specific malformations and shows a multifactorial etiology involving the interaction of genetic susceptibility with environmental factors. On the other hand, syndromic forms of CLP (5-7\% of CLP cases) consist of more than 200 different conditions and are characterized by the presence of a specific malformation pattern involving the presence of other associated anomalies in addition to CLP (Mossey et al., 2009).

Research has shown the association of some genes with NSCLP, including IRF6 (encoding interferon regulatory factor 6), MSX1 (encoding muscle segment homeobox 1), TBX22 (encoding T-box transcription factor 22), and PVRL1 (encoding poliovirus receptor-like 1) (Prescott et al., 2001; Jezewski et al., 2003; Marcano et al., 2004; Zucchero et al., 2004). PVRL1 is a member of the adhesin family of cell surface proteins that possess an immunoglobulin-related structure, and its main function relates to the formation of tight junctions between epithelial cells (Sözen et al., 2001). In addition, during development, the pair of palatal shelves must be elevated along with the development of the tongue, after which the palatal epithelium appose and fuse together. PVRL1 plays a crucial role in these processes. Mutations in PVRL1 have previously been found to have a significant relationship with CLP and ectodermal dysplasia 1 (Honda et al., 2003).

After the first report by Suzuki et al. (2000) that showed that the W185X homozygous loss-of-function mutation in PVRL1 could lead to a rare autosomal recessive syndrome, CLPectodermal dysplasia-1, a subsequent study from the same research team found that heterozygosity of the nonsense W185X mutation is a genetic risk factor for NSCLP in a northern Venezuelan population (Sözen et al., 2001). Thus, PVRL1, and particularly its coding region, has become a focus point in NSCLP research (Scapoli et al., 2004, 2006; Tseng et al., 2006; Tongkobpetch et al., 2008; Zhao et al., 2009); however, the results from different regions are discrepant (Table 1).

PVRL1 is divided into $\alpha-, \beta$-, and $\gamma$-isoforms. We used polymerase chain reaction (PCR) and direct sequencing analysis of polymorphisms in PVRL1 exons 2 and 5 in a Guangdong population, as well as single-base primer extension and matrix-assisted laser absorption ionization time of flight mass spectrometry (MALDI-TOF MS) in NSCLP patients from the Guangdong population in China, to ascertain genotypes at nucleotides 334, 391, and 1183 in the $\alpha$-isoform, and at nucleotide 1082 in the $\beta$-isoform. 


\begin{tabular}{lll}
\multicolumn{2}{l}{ Table 1. Asia PVRL1 genetic research results. } & \\
\hline Content & Area & Results \\
\hline All exons & Philippines & $\alpha$-subtype exon 2 S112T, T131A \\
& & $\beta$-subtype exon 6 G361V \\
$\alpha$-subtype exon 1-6 & Thailand & $\alpha$-subtype exon 6 V395M \\
$\alpha$-subtype exon 3 & China JIANG-ZHE & None \\
$\alpha$-subtype exon 3/5 & China TANWAN & None \\
9 SNP positions & Japan & No significant difference \\
\hline
\end{tabular}

\section{MATERIAL AND METHODS}

\section{Reagents}

Genomic DNA was extracted from whole blood by using either the Takara whole blood genomic DNA extraction kit (Takara; Dalian, China) or the Biochemical Science and Technology Beijing blood genomic extraction kit (TianGen; Beijing, China). PCR primers were synthesized by Shanghai Biological Engineering Technology Health Synthesis. TaKaRa Ex Taq (Takara) was used for PCR.

\section{Patient information}

Informed written consent was obtained from all subjects in the study, and ethical approval was provided by the Ethics Committee of the Second Affiliated Hospital of Shantou University Medical College prior to the start of the study. Blood samples were collected between February and October 2009 from 171 hospitalized patients with NSCLP in the Cleft Lip and Palate Treatment Center, the Second Affiliated Hospital of Shantou University Medical College, and from 100 healthy volunteers in Shantou University Medical College. Blood samples were collected in 2 EDTA anticoagulant vials and stored at $-80^{\circ} \mathrm{C}$ (group in Table 2). Other than NSCLP, all volunteers included in the study displayed normal growth and development, and had no other obvious abnormalities, including visual and auditory disturbances.

\begin{tabular}{|c|c|c|c|c|c|c|c|c|}
\hline \multirow[t]{2}{*}{ Group } & \multirow[t]{2}{*}{ Age } & \multicolumn{2}{|c|}{ Gender } & \multicolumn{3}{|c|}{ Type of cleft } & \multirow[t]{2}{*}{ Family history } & \multirow{2}{*}{$\begin{array}{l}\text { Virus infection } \\
\text { during pregnancy }\end{array}$} \\
\hline & & $\mathrm{M}$ & $\mathrm{F}$ & Cleft palate & Cleft lip & Cleft palate and lip & & \\
\hline Group A $(\mathrm{N}=71)$ & 3 months- 7 years & 47 & 24 & 11 & 22 & 38 & No & 5 \\
\hline Group B $(\mathrm{N}=38)$ & 3 months -37 years & 28 & 10 & 5 & 5 & 28 & Yes & Not clear \\
\hline$(\mathrm{N}=62)$ & 3 months -35 years & 41 & 21 & 14 & 15 & 33 & No & Not clear \\
\hline Control group $(\mathrm{N}=100)$ & $18-45$ years & 65 & 35 & No & No & No & No & No \\
\hline
\end{tabular}

\section{Experimental methods}

Direct sequencing of PVRL1 exons 2 and 5 was performed in 71 patients and 100 healthy volunteers. MALDI-TOF was performed for 100 patients and the same 100 healthy volunteers to assess nucleotides 334, 391, and 1183 in the $\alpha$-isoform, and nucleotide 1082 in the $\beta$-isoform. 


\section{PCR amplification}

PCR amplification of PVRL1 exons 2 and 5 was performed using the primers listed in Table 3. Each reaction tube contained: $0.25 \mu \mathrm{L} 5 \times 10^{6} \mathrm{U} / \mathrm{L}$ TaKaRa Ex Taq, $5 \mu \mathrm{L} 10 \mathrm{X}$ Ex Taq Buffer $\left(\mathrm{Mg}^{2+}\right.$-free), $4 \mu \mathrm{L} 25 \mathrm{mM} \mathrm{MgCl}, 4 \mu \mathrm{L} 2.5 \mathrm{mM}$ of each dNTP mixture, $0.5 \mu$ g genomic DNA, $1 \mu \mathrm{L} 20 \mu \mathrm{M}$ of each upstream and downstream primer, and distilled water to a total volume of $50 \mu \mathrm{L}$. The exon 2 reaction conditions were as follows: $94^{\circ} \mathrm{C}$ for $30 \mathrm{~s}, 58^{\circ} \mathrm{C}$ for 30 s, and $72^{\circ} \mathrm{C}$ for $30 \mathrm{~s}$ for 35 cycles. The exon 5 reaction conditions were as follows: $94^{\circ} \mathrm{C}$ for 30 $\mathrm{s}, 57^{\circ} \mathrm{C}$ for $30 \mathrm{~s}$, and $72^{\circ} \mathrm{C}$ for $40 \mathrm{~s}$ for 35 cycles. Five microliters PCR product was subjected to $3 \%$ agarose gel electrophoresis (Figure 1).

Table 3. Primers of $P V R L 1$ for polymerase chain reaction.

\begin{tabular}{lllcc}
\hline Exons & Primer $\left(5^{\prime}-3^{\prime}\right)$ & Primer $\left(5^{\prime}-3^{\prime}\right)$ & Tm $\left({ }^{\circ} \mathrm{C}\right)$ & Length $(\mathrm{bp})$ \\
\hline Exons 2 & CTGTGCCTGACACTGACCAC & AGGTCACAGGCCTCTGGATG & 57 & 441 \\
Exons 5 & CCTACGCTGTGTCTCCCACT & GGAGAGGCTGGGGAGGAT & 58 & 210 \\
\hline
\end{tabular}

$\mathrm{Tm}=$ melting temperature.

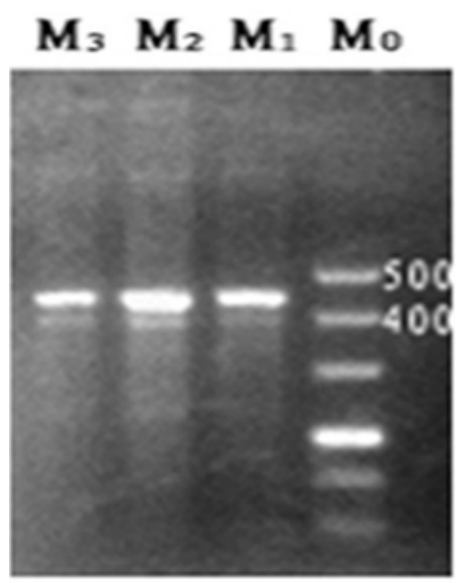

A

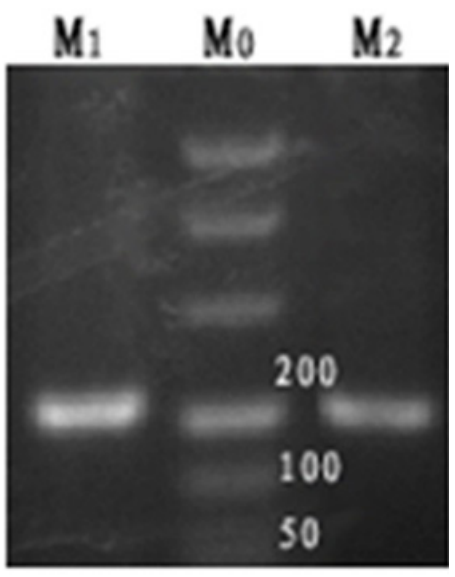

B

Figure 1. Agarose electrophoresis of PCR products of exons 2 and 5. A. Exon 2 PCR products. Lane $M_{0}=$ marker; lanes $M_{1-3}=$ exon 2 PCR products (441 bp). B. Exon 5 PCR products. Lane $M_{0}=$ marker; lanes $M_{1-2}=$ exon 5 PCR products (210 bp).

\section{DNA sequence analysis}

PCR products derived from 71 patients were sequenced directly by Shanghai Benegene Biotechnology Co., Ltd using the ABI Prism ${ }^{\mathrm{TM}}$ BigDye $^{\mathrm{TM}}$ Terminator Cycle Sequencing kit and the ABI Prism 3730 capillary sequencer (Applied Biosystems). The Chromas software (Technelysium; South Brisbane, Australia) was used to analyze the sequencing traces, and the DNAMAN software (Lynnon Biosoft; Quebec, Canada) was used to compare the sequences of NSCLP patients with those of the control group. 


\section{Mass spectrometry}

Genomic DNA samples of 100 patients were subjected to single nucleotide polymorphism (SNP) genotyping by the Mysterious Chi Biological Technology Co., Ltd. (Shanghai, China). The technology involved a combination of single-base primer extension and MALDI-TOF analysis with a MassARRAY system (Sequenom). The primers used are listed in Table 4.

\begin{tabular}{|c|c|c|c|c|}
\hline Base sites & Primer $\left(5^{\prime}-3^{\prime}\right)$ & Primer $\left(5^{\prime}-3^{\prime}\right)$ & $\operatorname{Tm}\left({ }^{\circ} \mathrm{C}\right)$ & Length (bp) \\
\hline 334 (asubtype) & ACGTTGGATGCCTTCACCGATGGCACTATC & ACGTTGGATGAGGTAGCAAACTCGCAGATG & 57.8 & 98 \\
\hline 391 (asubtype) & ACGTTGGATGATCACCGTGAGATTGAGCTG & ACGTTGGATGATGAGGGTGTCTACATCTGC & 52.7 & 96 \\
\hline 1082 (ßsubtype) & ACGTTGGATGCACAGCTGTCTGACATCAAG & ACGTTGGATGAGAGCTAGGATGTTCTGAGG & 56.5 & 94 \\
\hline 1183 (asubtype) & ACGTTGGATGACACCTTCAAGGGTGACTAC & ACGTTGGATGGATGCCTGCCTTGCTGTAG & 57.8 & 88 \\
\hline
\end{tabular}

$\mathrm{Tm}=$ melting temperature.

\section{PCR conditions}

Prior to primer extension, PCR was performed using the following conditions: $94^{\circ} \mathrm{C}$ for $15 \mathrm{~min} ; 94^{\circ} \mathrm{C}$ for $20 \mathrm{~s}, 56^{\circ} \mathrm{C}$ for $30 \mathrm{~s}$, and $72^{\circ} \mathrm{C}$ for $1 \mathrm{~min}$ for $45 \mathrm{cycles}$, followed by a final extension step at $72^{\circ} \mathrm{C}$ for $3 \mathrm{~min}$. Following PCR, the remaining dNTPs were digested with phosphoric acid, and the reaction mixture included $1.53 \mu \mathrm{L}$ water, $0.17 \mu \mathrm{L}$ SAP buffer, and $0.3 \mathrm{U}$ alkaline phosphatase (Sequenom). The reaction proceeded at $37^{\circ} \mathrm{C}$ for $40 \mathrm{~min}$, followed by incubation at $85^{\circ} \mathrm{C}$ for $5 \mathrm{~min}$ to inactivate the enzymes. After alkaline phosphatase treatment, the initial 20-25 bases from the SNP sites were selected as primers. Single nucleotide primer extension was carried out in the following reaction: $0.2 \mu \mathrm{L} 10 \mathrm{X}$ iPLEX buffer, $0.041 \mu \mathrm{L}$ iPLEX enzyme (Sequenom), $0.084 \mu \mathrm{L} 10 \mu \mathrm{M}$ extension primer, $0.2 \mu \mathrm{L}$ termination mixture, and water to a total volume of $2 \mu \mathrm{L}$. The single base extension reaction was carried out under the following conditions: $94^{\circ} \mathrm{C}$ for $30 \mathrm{~s}$; followed by $94^{\circ} \mathrm{C}$ for $5 \mathrm{~s}, 52^{\circ} \mathrm{C}$ for $5 \mathrm{~s}$, and $80^{\circ} \mathrm{C}$ for $5 \mathrm{~s}$ for a total of 40 cycles, followed by a final step at $72^{\circ} \mathrm{C}$ for $3 \mathrm{~min}$. The terminated reactants were desalted by adding $25 \mu \mathrm{L}$ water and $6 \mathrm{mg}$ cation exchange resin (Sequenom). Using the MassARRAY Nanodispenser (Sequenom), the final product of each sample was applied to a 384-well spectroCHIP plate (Sequenom), and used for MALDI-TOF MS. Control group results were used for comparison of the sequences.

\section{RESULTS}

We used the Chromas software to analyze the sequencing peak photos, and the DNAMAN software to compare sequences to the controls (Figure 2). Following sequencing of the PCR products, the specific sequences of exons 2 and 5 of PVPL1 were identified. No mutations were found for any of the 71 patients or for the controls at codons 112 and 131 in exon 2, or at codon 323 in exon 5. The results were consistent when using either DNAMAN or Chromas. 

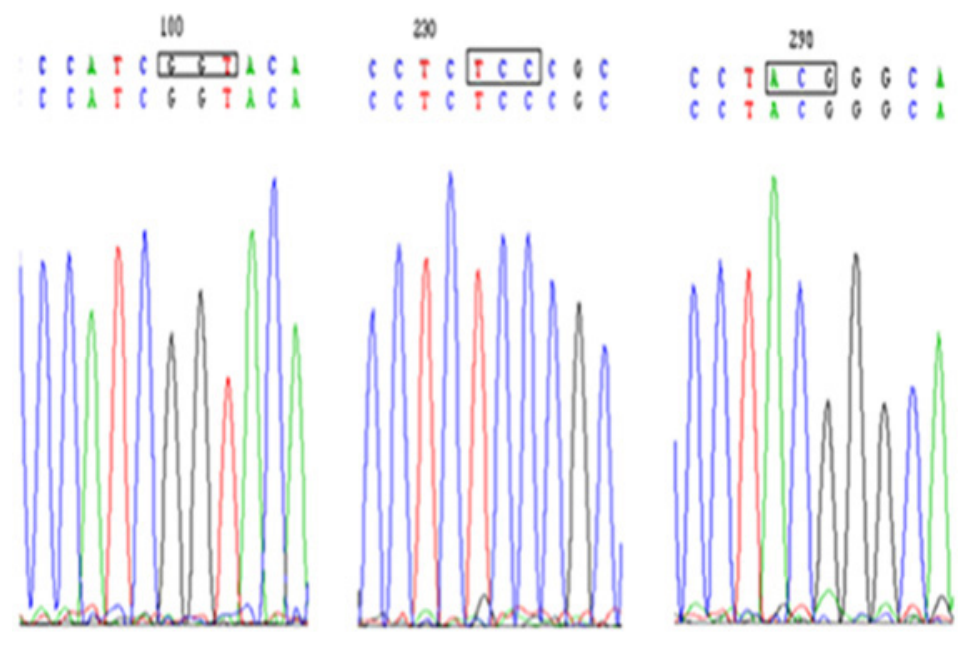

A

B

C

Figure 2. Analysis of sequences using the Chromas and the DNAMAN softwares. A. No mutation was present at codon 323 (GGT > GGTT) in exon 5. B. No mutation was present at codon 112 (TTC > ACC) in exon 2. C. No mutation was present in codon 131 (ACG > GCG) in exon 2.

TOF-MS analysis demonstrated SNP classification of the $\alpha$-isoform at the 334, 391, and 1183 sites and the $\beta$-isoform at the 1082 site (Figure 3 ). In these images, only a single yellow line was observed, indicating that all of these sites were homozygous, and that there were no mutations in any of these sites compared to the controls (Table 5).

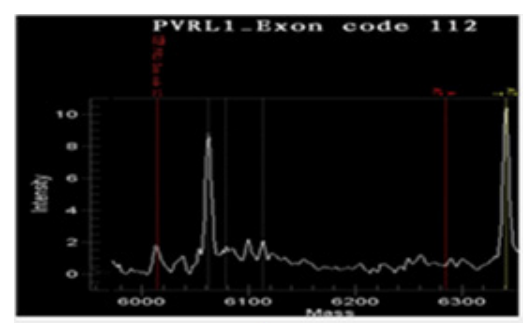

A

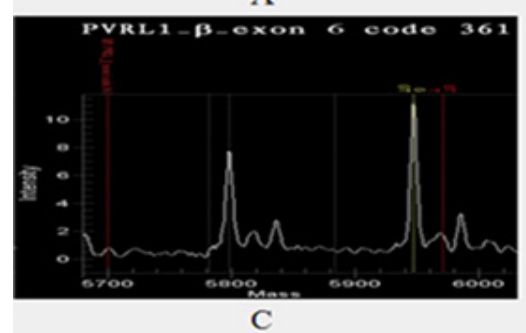

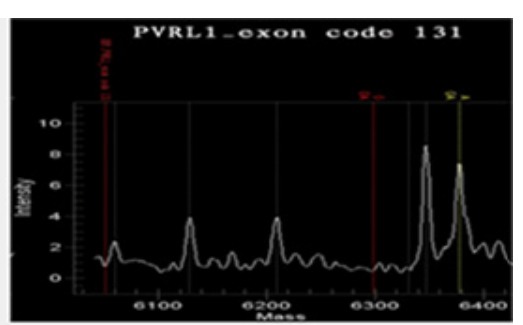

B

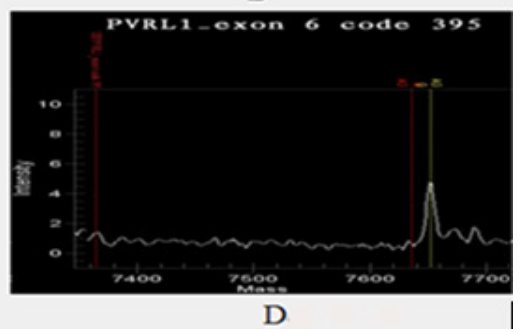

Figure 3. Time of flight mass spectrometry analysis. A. No $\mathrm{T}>\mathrm{A}$ mutation was present at position 112 of the $\alpha$-isoform. B. No A $>$ G mutation was present at position 131 of the $\alpha$-isoform. C. No G $>$ A mutation was present at position 361 of the $\beta$-isoform. D. No G > A mutation was present at position 395 of the $\alpha$-isoform. 
Table 5. Single-nucleotide polymorphism typing results.

\begin{tabular}{lc}
\hline Base sites & SNP typing (experimental group frequency, control group frequency) \\
\hline $334(\alpha$ subtype $)$ & $\mathrm{T} / \mathrm{T}(100,100)$ \\
$391(\alpha$ subtyp $)$ & $\mathrm{A} / \mathrm{A}(100,100)$ \\
$1082(\beta$ subtyp $)$ & $\mathrm{G} / \mathrm{G}(100,100)$ \\
$1183(\alpha$ subtype $)$ & $\mathrm{G} / \mathrm{G}(100,100)$ \\
\hline
\end{tabular}

We also found that there were no mutations in nucleotides 334,391 , and 1183 in the $\alpha$-isoform, or in nucleotide 1082 in the $\beta$-isoform by comparing the sequences of the experimental and control groups.

\section{DISCUSSION}

Based on previous research, this study aimed to verify the association between PVRL1 mutations and NSCLP in patients from the Guangdong region.

Congenital CLP is a common disease, with a worldwide incidence of 0.04-0.2 (Schutte and Murray, 1999), an incidence of $2.6 \%$ in Asian individuals, and 3.6\% in American individuals, whereas in Southern China, the incidence is approximately $1.25 \%$ (Liang et al., 2006). NSCLP accounts for 70\% of all CLP cases; although its etiology is unknown, it is generally considered to result from a combination of genetic and environmental factors.

PVRL1 is located in the q23.2 region of chromosome 11, and encodes an immunoglobulin family member that is important for cell-cell adhesion in epithelia. Suzuki et al. (2000) found mutations in PVRL1 codons 185 (TGG $\rightarrow$ T-G) and 323 (GGT $\rightarrow$ GGTT) in patients with ectodermal dysplasia syndrome; subsequently, syndromic CLP patients in Northern Venezuela were also found to carry the codon $185(\mathrm{TGG} \rightarrow \mathrm{T}-\mathrm{G})$ mutation $(\mathrm{P}<0.01)$ (Sözen et al., 2001). This mutation leads to truncation of the protein.

Recent research has investigated the association between PVRL1 and NSCLP, including the gene-environment and gene-gene interactions. Scapoli et al. $(2004,2006)$ did not find the W185X mutation in the populations studied, but instead found R199Q, R210H, and R212H mutations, affecting conserved amino acids (Avila et al., 2006). In Norway, the Philippines, and South America, 23 people carrying NSCLP-related mutations were identified; these mutations included 11 in the coding region, 7 in introns, and another 7 in the $\mathrm{CpG}$ islands. In European populations, CLMPT 1, the intronic mutation S7-10G/A, and exonic mutations Gly331Gly, Ala88Ala, and Pro309Pro, combined with PVRL1 Glu441-Gly442 Glu insertion mutations, were found to occur simultaneously, which may represent genetic factors predisposing individuals to NSCLP.

In Asian populations, fewer mutations in PVRL1 have been reported (Table 1); however, in the Chinese mainland, little research has been performed on the association between PVRL1 and NSCLP. Marazita et al. (2002) have reported gene mapping for NSCLP in the Chinese population, but the chromosomal regions identified did not overlap with regions identified in European and American Caucasian patients. Tongkobpetch et al. (2008) identified the S112T, T131A, and G361V mutations in Thai patients with NSCLP; in contrast, in Taiwan (exons 2 and 5), the Zhejiang region of Mainland China (exon 3), and Japan (9 SNP sites), no meaningful associations of genetic variants and NSCLP were found. The S112T and T131A mutations occur in the vicinity of key amino acids in a region of PVRL1 previously shown to 
mediate cell-cell adhesion and cell-virus adhesion (Struyf et al., 2002). The G361V mutation occurs in the transmembrane region and is considered to be likely to affect PVRL1 structure, and the V395M mutation occurs in the extracellular region of the membrane protein.

In order to expand research regarding the relationship between PVRL1 mutations and NSCLP in patients from Mainland China, we here examined 171 NSCLP patients from Guangdong. We screened 71 people for mutations in exons 2 and 5 of PVRL1, and another group of 100 individuals, 38 of which had a family history of CLP, were examined by TOFMS. None of the mutations previously found in Asian patients, i.e., S112T, T131A, G361V, or V395M, were present in our patients or in a control group of 100 volunteers. Although the results of our study do not corroborate with those of Caucasian populations, our results were consistent with those obtained from Chinese patients from Taiwan and Zhejiang Province of Mainland China. Thus, mutations in exons 2 and 5, and in codons 112, 131, 361, and 395 of PVRL1 do not play a role in NSCLP in the Chinese population.

\section{ACKNOWLEDGMENTS}

The authors thank all of the participants in this study, and also thank Weilian Chen and Shen-rong $\mathrm{Wu}$ for sample and data collection. The authors would also like to thank Shanghai Benegene Biotechnology for genotyping and sequencing, and Jason Liu from EnuoTech for revising this manuscript. Research supported by grants from the Guangdong Natural Science Foundation (\#9151503104000001) and the National Science Foundation for Young Scientists of China (\#81001284).

\section{REFERENCES}

Avila JR, Jezewski PA, Vieira AR, Orioli IM, et al. (2006). PVRL1 variants contribute to non-syndromic cleft lip and palate in multiple populations. Am. J. Med. Genet. A 140: 2562-2570.

Honda T, Shimizu K, Fukuhara A, Irie K, et al. (2003). Regulation by nectin of the velocity of the formation of adherens junctions and tight junctions. Biochem. Biophys. Res. Commun. 306: 104-109.

Jezewski PA, Vieira AR, Nishimura C, Ludwig B, et al. (2003). Complete sequencing shows a role for MSX1 in nonsyndromic cleft lip and palate. J. Med. Genet. 40: 399-407.

Liang J, Wang YP and Zhou GX (2006). Nonsyndromic cleft lip in south China epidemiology. Clin. Oral Med. Mag. 16: 122-123.

Marazita ML, Field LL, Cooper ME, Tobias R, et al. (2002). Nonsyndromic cleft lip with or without cleft palate in China: assessment of candidate regions. Cleft Palate Craniofac. J. 39: 149-156.

Marcano AC, Doudney K, Braybrook C, Squires R, et al. (2004). TBX22 mutations are a frequent cause of cleft palate. $J$. Med. Genet. 41: 68-74.

Mossey PA, Little J, Munger RG, Dixon MJ, et al. (2009). Cleft lip and palate. Lancet 374: 1773-1785.

Prescott NJ, Winter RM and Malcolm S (2001). Nonsyndromic cleft lip and palate: complex genetics and environmental effects. Ann. Hum. Genet. 65: 505-515.

Scapoli L, Palmieri A, Pezzetti F, Carinci F, et al. (2004). Investigation of the W185X nonsense mutation of PVRL1 gene in Italian nonsyndromic cleft lip and palate patients. Am. J. Med. Genet. A 127A: 211.

Scapoli L, Palmieri A, Martinelli M, Vaccari C, et al. (2006). Study of the PVRL1 gene in Italian nonsyndromic cleft lip patients with or without cleft palate. Ann. Hum. Genet. 70: 410-413.

Schutte BC and Murray JC (1999). The many faces and factors of orofacial clefts. Hum. Mol. Genet. 8: 1853-1859.

Sözen MA, Suzuki K, Tolarova MM, Bustos T, et al. (2001). Mutation of PVRL1 is associated with sporadic, nonsyndromic cleft lip/palate in northern Venezuela. Nat. Genet. 29: 141-142.

Struyf F, Martinez WM and Spear PG (2002). Mutations in the N-terminal domains of nectin-1 and nectin-2 reveal differences in requirements for entry of various alphaherpesviruses and for nectin-nectin interactions. J. Virol. 76: 12940-12950. 
Suzuki K, Hu D, Bustos T, Zlotogora J, et al. (2000). Mutations of PVRL1, encoding a cell-cell adhesion molecule/ herpesvirus receptor, in cleft lip/palate-ectodermal dysplasia. Nat. Genet. 25: 427-430.

Tongkobpetch S, Suphapeetiporn K, Siriwan P and Shotelersuk V (2008). Study of the poliovirus receptor related-1 gene in Thai patients with non-syndromic cleft lip with or without cleft palate. Int. J. Oral Maxillofac. Surg. 37: 550-553.

Tseng YT, Hsiao HH, Hsiao HP, Tsai WC, et al. (2006). A study of PVRL1 mutations for non-syndromic cleft lip and/or palate among Taiwanese patients. Int. J. Oral Maxillofac. Surg. 35: 453-455.

Zhao X, Jiang RS, Liu R, Ye WS, et al. (2009). Relationship of nonsyndromic cleft lip and/or palate and poliovirus receptor-related 1 exon 3 polymorphisms in Han people of Jiangzhe area. Zhonghua Zheng Xing Wai Ke Za Zhi 25: 31-33.

Zucchero TM, Cooper ME, Maher BS, Daack-Hirsch S, et al. (2004). Interferon regulatory factor 6 (IRF6) gene variants and the risk of isolated cleft lip or palate. N. Engl. J. Med. 351: 769-780. 